\title{
Investigation of Positional Differences in Fitness of Male University Ice Hockey Players and the Frequency, Time Spent and Heart Rate of Movement Patterns During Competition
}

Joel Jackson ${ }^{1}$, Gary Snydmiller ${ }^{2}$, Alex Game ${ }^{1}$, Pierre Gervais ${ }^{1}$, Gordon Bell ${ }^{1 *}$

${ }^{1}$ Faculty of Physical Education and Recreation, University of Alberta, Edmonton, Alberta Canada, T6G2H9

${ }^{2}$ Augustana Faculty, University of Alberta, Camrose, Alberta Canada, T4V2R3

Corresponding Author: Gordon Bell, E-mail: bell.gordon@gmail.com

\section{ARTICLE INFO}

Article history

Received: May 22, 2017

Accepted: June 20, 2017

Published: July 31, 2017

Volume: 5 Issue: 3

Conflicts of interest: None

Funding: None

\begin{abstract}
Background: Men's university ice hockey has received little scientific attention over the past 30 years, a time in which the traits of the players and the demands of the game have evolved. Objectives: This study compared the physiological characteristics of university ice hockey players and examined the frequency and duration of the different movement patterns and heart rate (HR) responses during competition. Methods: Twenty male ice hockey players from the same team ( $\overline{\mathrm{X}}$ age $\pm \mathrm{SD}=22 \pm 2$ years) underwent a fitness evaluation and were filmed and HR monitored during regular season games. Results: Forwards and defense had similar fitness and only differed on $\%$ fatigue index and peak heart during on-ice sprinting $(\mathrm{P}<0.05)$. Defense stood, glided and skated backwards more than forwards and forwards skated at a moderate intensity and glided forward more than defense $(\mathrm{P}<0.05)$. All players spent the majority of game time gliding forward ( $60 \%$ of the time) followed by skating forward at a moderate intensity $(17 \%)$ and standing with little movement (9\%). Average HR during the game reached 96 and $92 \%$ and peak HR was 100 and $96 \%$ of maximum in forwards and defense, respectively. Conclusions: Male university hockey players present with a high level of physical fitness in a variety of categories with few differences between forwards and defense. Movement patterns during games suggest that players are performing low to moderate intensity on-ice activities the majority of the time. Paradoxically, HR continues to climb to near maximum during on ice shifts.
\end{abstract}

Key words: Time Motion Analysis, Positional Differences, Performance

\section{INTRODUCTION}

Ice hockey is a popular team sport primarily played in North America and Europe. It is conducted on ice with skates and full body equipment and includes three, twenty minute periods where players, excluding the goaltender, substitute on and off the ice in shifts of varying lengths (e.g., 45-90s) depending on the flow of the game and coaching decisions (Green, Bishop, Houston, McKillop, Norman \& Stothart, 1976; Cox, Miles, Verde \& Rhodes, 1995; Jackson, Snydmiller, Game, Gervais \& Bell, 2016). Competitive ice hockey requires a high level of skill and tactical awareness and is characterized by repeated bouts of high intensity sprinting $(<5 \mathrm{~s})$, directional changes and body contact interspersed with rest periods of low intensity activity such as gliding, standing, struggling with other players, and other movements (Montgomery, 1988; Cox et al, 1995; Bracko, Fellingham, Hall, Fisher \& Cryer, 1998; Jackson et al, 2016). Furthermore, there are three primary positions in ice hockey that can be separated into forwards (left wing, right wing and center), defense (right and left) and a goaltender that have different duties and possibly different physiological profiles (Vescovi, Murray, Fiala \& Vanbeest, 2006; Burr, Jamnik, Baker, MacPherson, Gledhill \& McGuire, 2008; Bell, Snydmiller $\&$ Game, 2008). It has been reported that the overall intensity of ice hockey games is high and this requires players to possess exceptional anaerobic, aerobic and musculoskeletal fitness and a mesomorphic body type (Cox et al., 1995; Geithner, Lee, \& Bracko, 2006; Stanula \& Roczniok, 2014). It is also evident that there has been a significant increase in player size, strength, leanness and aerobic fitness over the past three decades indicating a change has occurred in the characteristics of the player and demands of the game especially at the professional level (Montgomery, 2006; Quinney, Dewart, Game, Snydmiller, Warburton \& Bell, 2008). However, whether this has occurred at other levels of ice hockey has not been scientifically documented.

To evaluate the demands of a sport and the physiological requirements of competition, research generally focuses on a fitness evaluation of the players; an analysis of the type, frequency and duration of the different activities featured in the 
sport; and, measurement of various physiological indicators of the intensity of the movement patterns during the game (Cox et al., 1995; Bracko, 2001; Geithner et al., 2006; Barris \& Button, 2008; Bell et al., 2008; Peterson, Fitzgerald, Dietz, Ziegler, Ingraham, Baker \& Snyder, 2015; Jackson et al., 2016). This type of research provides a more complete understanding of the sport and can offer insight into fitness components, game performance characteristics, positional differences, coaching tactics and more specific strength and conditioning methods (Barris \& Button, 2008; Taylor, 2003). There are some investigations that have reported fitness of ice hockey players as well as time motion characteristics of ice hockey games at a variety of competitive levels, some in combination with physiological measurements in men, women and youth, but research investigating University level players and competition has been limited and dated (Green et al., 1976). Furthermore, this latter research (Green et al., 1976) provided only partial movement analyses. Therefore, the purpose of this study was to measure the physiological characteristics of male university ice hockey players; examine the frequency and time spent performing various movements during ice hockey games; and, to assess the heart rate demands of ice hockey games. Supported by our recent research in female university ice hockey (Jackson et al., 2016), it was hypothesized that ice hockey players will present with high levels of conditioning, especially anaerobic fitness and muscular power parameters. As well, the frequency of and time spent performing movement patterns during games will favor gliding and moderate intensity activity and cardiovascular demands of the game will be intense as indicated by high HR responses. Furthermore, a comparison of these parameters between players in the forward and defense positions were conducted.

\section{METHODS}

\section{Participants}

The participants were 20 male ice hockey players (13 forwards and 7 defensemen) with a mean age of $22 \pm 2$ (SD) that belonged to the same University team. Age, anthropometric and fitness results are presented in Table 1. A verbal and written explanation of the study was provided and each volunteer signed a physical activity readiness questionnaire (PAR-Q) and an informed consent form. This study was approved by a University of Alberta Research Ethics Board.

\section{Experimental Approach to the Problem}

This study included a convenient sample of players belonging to the same University Hockey Team that were silver medalists at the University Sports National Championships during the same year this study was conducted. Players in the forward (center, right wing, left wing) and defense (right, left) position were examined with the goaltenders being excluded from the present analysis. Each player completed a series of standardized fitness tests (Table 1). A time motion analysis (TMA) was used to determine the frequency and duration that players performed at different movements
Table 1. Participant fitness testing results

\begin{tabular}{lcc}
\hline Measurement & $\begin{array}{c}\text { Forward } \\
(\mathbf{n}=7)\end{array}$ & $\begin{array}{c}\text { Defense } \\
(\mathbf{n}=\mathbf{1 3})\end{array}$ \\
\hline Age $(\mathrm{yrs})$ & $22 \pm 1$ & $22 \pm 2$ \\
Height $(\mathrm{cm})$ & $179.2 \pm 6.9$ & $180.9 \pm 3.9$ \\
Weight $(\mathrm{kg})$ & $84.4 \pm 6.7$ & $84.3 \pm 6.3$ \\
Body fat $(\%)$ & $10.7 \pm 1.5$ & $10.9 \pm 2.1$
\end{tabular}

5 s Repeated anaerobic cycle test (RACT)

$\begin{array}{lcc}\text { Peak 5 s anaerobic PO }(\mathrm{w}) & 1324.0 \pm 150.0 & 1345.3 \pm 132.5 \\ \text { Peak 5 s anaerobic } & 15.6 \pm 0.6 & 15.9 \pm 0.9 \\ \text { PO }\left(\mathrm{w} \times \mathrm{kg}^{-1}\right) & & \\ \text { Mean anaerobic PO }(\mathrm{w}) & 1187.3 \pm 126.0 & 1160.2 \pm 97.4 \\ \text { Mean anaerobic PO }\left(\mathrm{w} \times \mathrm{kg}^{-1}\right) & 14.1 \pm 0.7 & 13.8 \pm 0.9 \\ \text { Fatigue index }(\%) & 23 \pm 6 & 28 \pm 4 *\end{array}$

$15 \mathrm{~m}$ repeated on ice sprint test (ROIST)

\begin{tabular}{|c|c|c|}
\hline $5 \mathrm{~m}$ skating sprint time (s) & $1.09 \pm 0.08$ & $1.13 \pm 0.09$ \\
\hline 15 m skating sprint time (s) & $2.53 \pm 0.11$ & $2.59 \pm 0.14$ \\
\hline $\begin{array}{l}5 \mathrm{~m} \text { skating sprint } \\
\text { velocity }\left(\mathrm{m} \times \mathrm{s}^{-1}\right)\end{array}$ & $4.62 \pm 0.33$ & $4.43 \pm 0.36$ \\
\hline $\begin{array}{l}15 \mathrm{~m} \text { skating sprint } \\
\text { velocity }\left(\mathrm{m} \times \mathrm{s}^{-1}\right)\end{array}$ & $5.93 \pm 0.26$ & $5.80 \pm 0.31$ \\
\hline $\begin{array}{l}\text { Skating sprint fatigue } \\
\text { index }(\%)\end{array}$ & $4 \pm 2$ & $5 \pm 3$ \\
\hline Mean HR during ROIST & $169 \pm 13$ & $161 \pm 8$ \\
\hline Peak HR during ROIST & $179 \pm 11$ & $170 \pm 6^{*}$ \\
\hline \multicolumn{3}{|l|}{ Musculo-skeletal fitness } \\
\hline Maximum curl-ups (\#) & $41 \pm 10$ & $46 \pm 16$ \\
\hline Maximum push-ups (\#) & $33 \pm 6$ & $29 \pm 6$ \\
\hline Combined grip strength (kg) & $137 \pm 17$ & $135 \pm 17$ \\
\hline Sit and reach flexibility $(\mathrm{cm})$ & $40.6 \pm 7.2$ & $43.7 \pm 6.3$ \\
\hline \multicolumn{3}{|l|}{ Lower \& upper body power } \\
\hline Vertical jump height $(\mathrm{cm})$ & $67.3 \pm 10.2$ & $64.2 \pm 12.6$ \\
\hline Vertical jump leg power (w) & $5869.6 \pm 716.3$ & $5645.8 \pm 801.7$ \\
\hline Medicine ball chest throw $(\mathrm{cm})$ & $470.8 \pm 57.8$ & $502.0 \pm 30.3$ \\
\hline \multicolumn{3}{|l|}{ Aerobic Fitness } \\
\hline $\mathrm{VO}_{2}$ at $\mathrm{VT}\left(\mathrm{L} \times \mathrm{min}^{-1}\right)$ & $3.62 \pm 0.49$ & $3.47 \pm 0.40$ \\
\hline HR at VT $\left(b \times \min ^{-1}\right)$ & $167 \pm 7$ & $165 \pm 10$ \\
\hline VT $\%$ of VO2peak & $78 \pm 4$ & $74 \pm 4$ \\
\hline $\mathrm{VO}_{2 \text { peak }}\left(\mathrm{L} \times \mathrm{min}^{-1}\right)$ & $4.64 \pm 0.54$ & $4.68 \pm 0.30$ \\
\hline $\mathrm{VO}_{2 \text { peak }}\left(\mathrm{ml} \times \mathrm{kg}-1 \times \min ^{-1}\right)$ & $54.9 \pm 4.8$ & $55.8 \pm 5.0$ \\
\hline Maximum heart rate $\left(b \times \min ^{-1}\right)$ & $182 \pm 10$ & $186 \pm 5$ \\
\hline
\end{tabular}

Values are given in $\overline{\mathrm{x}} \pm \mathrm{SD}$. $\mathrm{PO}=$ Power output; HR=Heart rate; $\mathrm{VO}_{2}=$ Oxygen uptake; $\mathrm{VT}=$ Ventilatory threshold. $*=$ Significantly different from forwards $(\mathrm{p}<0.05)$

during competitive league ice hockey games played in the same arena. To do this, two digital cameras were affixed to the wall at opposite sides of the arena at the center line and set to record complete games that were later downloaded and analyzed using a computer software program (Dartfish ${ }^{\odot}$ 
Team Pro 5.0, Fribourg, SUI). Three ice hockey games were videotaped at different times in the season (October 1, October 20 and November 19) after several exhibition and four league games were completed. These games were chosen by the investigators after advice from the coaching staff that the opponents would accurately reflect a competitive level of play indicative of Canadian University hockey. In support of this, there was a mean $( \pm$ SD) of $33 \pm 6$ versus $26 \pm 5$ shots on goal, $6 \pm 2$ versus $3 \pm 1$ goals scored and $6 \pm 4$ and $6 \pm 5$ penalties per game for the team reported in this research versus the opponents, respectively. Heart rate (HR) monitors were worn during each game and exercise testing. A complete rationale for this experimental design has been previously published by our research group (Jackson et al., 2016).

\section{Physiological Measurements.}

Each player underwent a series of standardized measurements in an exercise physiology laboratory. Age (years) was recorded, height $(\mathrm{cm})$ measured with a standiometer (Tanita Arlington, IL) and body mass (BM; kg) determined using a balance beam scale (HealthoMeter, Bridgeview, IL). A sum of the mean of 2 repeated skinfolds measurements (required to be within $5 \mathrm{~mm}$ of each other) taken at 6 different upper and lower body sites (subscapular, mid tricep, chest, iliac crest, abdomen and mid-thigh) using Harpenden calipers (West Sussex, UK) was calculated and used in a formula $\left[\%\right.$ body fat $=\left(\sum\right.$ of 6 skinfolds $\left.\left.\times 0.097\right)+3.64\right]$ to predict body fat percentage (Yuhasz, 1996; Forbes, Bell \& Kennedy, 2013).

Anaerobic fitness was measured using a five second repeated anaerobic cycling test (RACT) and a $15 \mathrm{~m}$ repeated on-ice sprint test (ROIST). The RACT has been previously validated and the reliability determined by our lab for ice hockey players (Wilson, Snydmiller, Game, Quinney \& Bell, 2010). Briefly, each player completed a standardized warm-up on a Monark Ergometric 894E Peak Bike (Monark, Vansbro SE) followed by four repeated, maximal sprints for five seconds separated by 10 s of active recovery against an individualized resistance setting $(0.095 \times \mathrm{BM}$ in $\mathrm{kg})$ for a total test time of $60 \mathrm{~s}$. The data was captured using a custom designed computer interface and software program (Wilson et al., 2010). Peak (highest 5 s power output; PO), mean (average $\mathrm{PO}$ of all 4 sprints and a fatigue index was calculated $\{(\%$ fatigue index $=[($ highest $5 \mathrm{~s}$ PO - lowest $5 \mathrm{~s}$ PO $) \div$ peak $5 \mathrm{~s}$ PO $] \times 100\}$. The ROIST involved seven repeats of maximal skating for a $15 \mathrm{~m}$ distance set within the neutral zone on the ice. The on ice set up was regularly moved to ensure that ice quality did not influence the test results. Players wore a complete set of equipment excluding their hockey sticks. Each maximal sprint started from a stationary position and continued for $15 \mathrm{~m}$, immediately followed by a low intensity skating return to the starting line prior to the start of the subsequent sprint that began exactly every $15 \mathrm{~s}$ for a total test time of $105 \mathrm{~s}$. A verbal count down of time was provided to each skater to ensure they returned to the start line, were completely stopped and ready for each sprint. Timing lights were used and positioned at the start and at $5 \mathrm{~m}$ and $15 \mathrm{~m}$ distances (Brower Timing Systems, Draper, and UT). Fast- est $5 \mathrm{~m}$ and $15 \mathrm{~m}$ time and velocity (v) as well as a fatigue index were calculated $\{(\%$ fatigue index $=[$ (fastest $15 \mathrm{~m} \mathrm{v}$ - slowest $15 \mathrm{~m} \mathrm{v}) \div$ fastest $15 \mathrm{~m} \mathrm{v}] \times 100\}$. Heart rate was measured during the ROIST test using a Polar ${ }^{\circledR}$ HR monitor set to memory for later analysis. Musculo-skeletal fitness was assessed according to established protocols. Maximum number of abdominal curl-ups was used to indicate abdominal muscular endurance (Quinney, Smith, \& Wenger, 1984; Quinney et al., 2008). In addition, maximum number of push-ups for upper body muscular endurance, maximum hand grip of both hands combined for forearm strength and maximum sit and reach forward flexion using a Wells-Dillon flexometer was performed to assess flexibility (Canadian Society for Exercise Physiology, 2013). Lower body muscular power was indicated using a maximal vertical jump test (Canadian Society for Exercise Physiology, 2013) conducted with a Vertec jump height measuring device (Gill Athletics, Champaign, IL). Maximum jump height was recorded and leg power was calculated according to the formula [leg power $(\mathrm{w})=(60.7 \times$ jump height in $\mathrm{cm})+(45.3 \times$ body mass in $\mathrm{kg})-2055$ ] of Sayers, Harackiewicz, Harman, Frykman \& Rosenstein (1999). Upper body muscular power was measured using a $5.5 \mathrm{~kg}$ seated medicine ball (Champion Sports, Marlboro, NJ) chest press style throw for maximum distance as reported by Gledhill and Jamnik (2007). Aerobic fitness was determined during a graded cycling exercise test to volitional exhaustion according to our protocol (Forbes et al., 2013). Briefly, each participant was provided with a standardized warm-up followed by an incremental protocol on a Monark $818 \mathrm{E}$ cycle ergometer until they were unable to continue (volitional fatigue). Respiratory gas exchange measurements were made using a Hans Rudolf valve assembly and headgear (Shawnee Mission, KS) that was attached to a calibrated metabolic measurement system (ParvoMedics, Sandy, UT). Ventilatory threshold was determined using the V-Slope method (Beaver, Wasserman \& Whipp, 1986) and peak oxygen uptake $\left(\mathrm{VO}_{2 \text { peak }}\right)$ was recorded as the highest $\mathrm{VO}_{2}$ achieved during the test. Heart rate was measured throughout the test using a Polar ${ }^{\circledR}$ heart rate monitor.

\section{Video Taping and Time Motion Analysis}

We have published recent research on the identical camera setup, recording, TMA, and reliability of measurement for all movement patterns during ice hockey games in the same arena (Jackson et al., 2016). In brief, two GoPro HD cameras (set at $720 \mathrm{p}$ and $60 \mathrm{fps}$ ) were positioned at the same height $(20 \mathrm{~m})$ from the ice surface on opposite walls of the area at center ice to ensure the complete ice surface ( 59.1 by $25.9 \mathrm{~m}$ ) was captured. The files associated with each game were downloaded and player movements were analyzed using Dartfish ${ }^{\odot}$ Team Pro 5.0 software (Fribourg, SUI). The software categorized the number of movement and time spent performing them as determined by a trained user with files exported to Excel for further analysis. The reliability (intra and inter observer, test retest) for coding movements and the frequency and time associated with each player using this technique was high as previously reported by our laboratory (Jackson et al., 2016). As well, the rationale for 
selection of the 10 primary different movement patterns performed in University ice hockey games has been justified and a complete description with examples have been reported by our lab (Jackson et al., 2016). The primary movements were: standing or little movement; forward accelerating skating start; gliding forward; moderate intensity forward skating; high or maximal intensity forward skating; accelerating backward skating start; gliding backward; moderate intensity backward skating; high or maximal intensity backward skating; and struggling for position or the puck with an opposing player.

\section{Game Heart Rate Measurements}

Polar $^{\circledR}$ Team Sport HR monitors were worn by 13 different players (9 forwards and 4 defense) and set to record $5 \mathrm{~s}$ average HR during each hockey game including the time between periods, as previously reported (Jackson et al., 2016). Seven players did not wear the monitors during the game for personal reasons feeling that it would be a distraction and/or a hindrance which may affect their performance.

\section{Data Analyses}

Data is presented as means $\pm \mathrm{SD}$. Percentage of total game time for each of the 10 movements was calculated for all players using Microsoft Excel ${ }^{\circledR}$ 2010. Separate one-way analysis of variance (ANOVA) was used to compare the fitness variables between positions. The TMA data and HR responses were collapsed across all three games for each player (see Jackson et al., 2016 for further rationalization). Separate 2 (positions) $\times 3$ (periods) ANOVA with repeated measures was used to compare the frequency of movements, movement time and HR between forwards and defense across each of the three periods of the game. A one-way ANOVA compared the number of movement frequencies, times and HR for the game totals by positions. Alpha was pre-set at $\mathrm{P}<0.05$. Statistica ${ }^{\mathrm{TM}}$ software was used for these latter analyses (Palo Alto, California).

\section{RESULTS}

A summary of the fitness variables for all players are shown in Table 1 . A significantly greater $\%$ fatigue index during the RACT test and a lower peak HR during the ROIST was observed in the defensemen compared to forwards with no difference being observed in mean and peak HR's during the ROIST between forwards and defense, with each achieving $91 \pm 8$ and $96 \pm 8 \%$ of HR max combined, respectively.

Players in the defense position stood, glided and skated backwards at a moderate intensity more frequently and for longer time than forwards $(\mathrm{P}<0.05$; Table 2$)$. Forwards skated at a moderate intensity significantly more frequently and for longer periods of time in the forward direction compared to defense. However, both positions struggled more frequently and for longer times in the third period compared to the first two periods with defense struggling more than forwards in periods one and two $(\mathrm{P}<0.05)$. There were more sprint starts in the forward direction by both forwards and defense in the third period and these occurred for longer periods of time for the forwards over the whole game $(\mathrm{P}<0.05)$. Forwards also glided for significantly longer periods of time in the forward direction compared to defense. Defense started sprinting backwards more often and for longer times compared to forwards during the whole game $(\mathrm{P}<0.05)$.

Figure 1 illustrates that the greatest time spent was associated with forward gliding on the ice for all players followed by forward skating at a moderate intensity, standing and backward gliding, sprint starts in the forward direction, struggling and forward maximal skating. The second greatest percentage of time spent for defense was gliding backwards and skating at a moderate intensity for forwards.

Heart rate responses did not differ between forwards and defense during ice hockey games (Table 3). Mean and peak HR responses during the game reached $94 \pm 3$ and $99 \pm 3 \%$ of HRmax for both positions, respectively. Heart rate recovered to levels significantly lower than mean and peak HR in between shifts. However, during the intermission periods

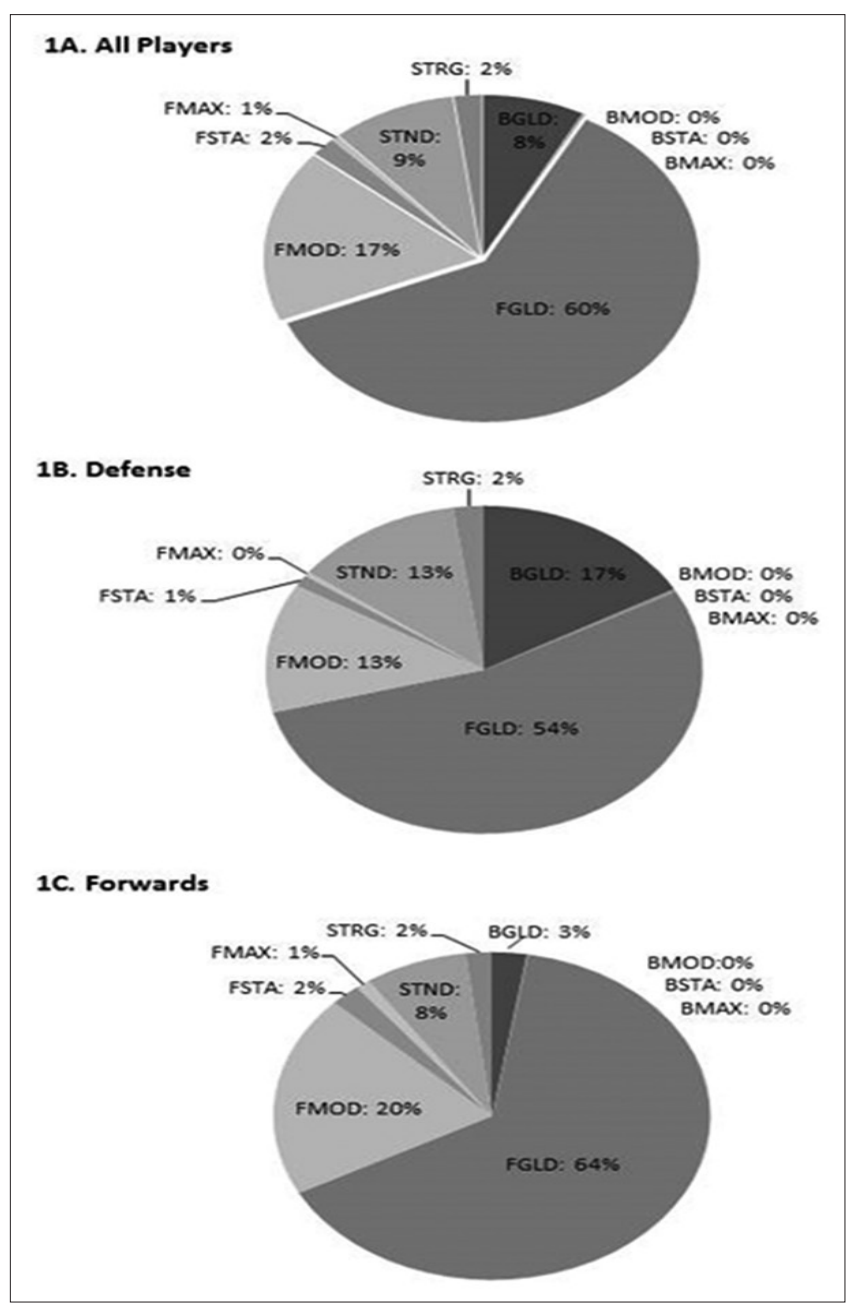

Figure 1. Percentage (\%) of time spent in each of the movement categories for all players (A), Defense (B) and Forwards (C) during male ice hockey games. STND = Standing; FSTA = Forward start; FGLD = Gliding/cruising forward; FMOD = Moderate intensity forward skating; FMAX = High/maximal intensity forward skating; BGLD $=$ Gliding/cruising backward; BMOD = Moderate intensity backward skating; STRG = Struggling 
Table 2. Mean $( \pm \mathrm{SD})$ frequency and duration in each of the movement categories for forwards and defense during men's ice hockey games

\begin{tabular}{|c|c|c|c|c|c|c|c|c|c|}
\hline \multirow[t]{2}{*}{ MC } & \multirow[t]{2}{*}{ Position } & \multicolumn{4}{|c|}{ Frequency } & \multicolumn{4}{|c|}{ Duration (s) } \\
\hline & & P1 & $\mathbf{P 2}$ & P3 & Game total & P1 & P2 & P3 & Game total \\
\hline \multirow[t]{2}{*}{ STND } & $\mathrm{D}$ & $14 \pm 3^{a}$ & $13 \pm 3^{\mathrm{a}}$ & $14 \pm 4^{a}$ & $41 \pm 4^{a}$ & $32.4 \pm 9.8^{\mathrm{a}}$ & $27.2 \pm 9.8^{\mathrm{a}}$ & $31.5 \pm 11.7^{\mathrm{a}}$ & $91.1 \pm 16.3^{\mathrm{a}}$ \\
\hline & $\mathrm{F}$ & $11 \pm 3$ & $15 \pm 10$ & $9 \pm 2$ & $30 \pm 4$ & $19.4 \pm 5.5$ & $17.5 \pm 6.5$ & $16.7 \pm 5.1$ & $53.5 \pm 7.0$ \\
\hline \multirow[t]{2}{*}{ FSTA } & $\mathrm{D}$ & $3 \pm 1$ & $3 \pm 1$ & $5 \pm 2^{b}$ & $11 \pm 3$ & $1.5 \pm 0.6^{\mathrm{a}}$ & $1.8 \pm 0.8^{\mathrm{a}}$ & $5.0 \pm 3.8^{\mathrm{a}, \mathrm{b}}$ & $8.3 \pm 4.1^{\mathrm{a}}$ \\
\hline & $\mathrm{F}$ & $3 \pm 2$ & $3 \pm 1$ & $6 \pm 4^{b}$ & $12 \pm 5$ & $3.8 \pm 3.0$ & $3.0 \pm 1.8$ & $9.0 \pm 7.8^{\mathrm{b}}$ & $15.9 \pm 7.9$ \\
\hline \multirow[t]{2}{*}{ FGLD } & $\mathrm{D}$ & $35 \pm 6$ & $31 \pm 6$ & $32 \pm 11$ & $98 \pm 9$ & $144.1 \pm 26.8^{\mathrm{a}}$ & $124.8 \pm 28.4^{\mathrm{a}}$ & $121.0 \pm 35.8^{\mathrm{a}}$ & $390.0 \pm 37.6^{\mathrm{a}}$ \\
\hline & $\mathrm{F}$ & $35 \pm 8$ & $32 \pm 5$ & $31 \pm 6$ & $98 \pm 13$ & $157.1 \pm 44.2$ & $145.7 \pm 26.4$ & $150.2 \pm 45.3$ & $452.9 \pm 76.1$ \\
\hline \multirow[t]{2}{*}{ FMOD } & $\mathrm{D}$ & $14 \pm 4^{\mathrm{a}}$ & $12 \pm 3^{\mathrm{a}}$ & $23 \pm 4^{\mathrm{a}, \mathrm{b}}$ & $49 \pm 9^{a}$ & $19.9 \pm 6.0$ & $15.8 \pm 4.5$ & $57.1 \pm 32.7^{\mathrm{b}}$ & $92.7 \pm 38.3^{\mathrm{a}}$ \\
\hline & $\mathrm{F}$ & $21 \pm 6$ & $21 \pm 4$ & $25 \pm 9^{b}$ & $66 \pm 15$ & $34.5 \pm 12.5$ & $39.9 \pm 35.6$ & $65.3 \pm 32.2^{\mathrm{b}}$ & $139.7 \pm 65.4$ \\
\hline \multirow[t]{2}{*}{ FMAX } & $\mathrm{D}$ & $1 \pm 1$ & $2 \pm 1$ & $2 \pm 1$ & $6 \pm 2$ & $0.7 \pm 0.7$ & $1.0 \pm 0.8$ & $1.5 \pm 1.3$ & $3.1 \pm 1.7$ \\
\hline & $\mathrm{F}$ & $1 \pm 1$ & $1 \pm 1$ & $2 \pm 1$ & $4 \pm 2$ & $1.4 \pm 1.2$ & $1.2 \pm 1.6$ & $1.6 \pm 1.2$ & $4.3 \pm 2.9$ \\
\hline \multirow[t]{2}{*}{ BSTA } & $\mathrm{D}$ & $0 \pm 0$ & $0 \pm 0$ & $0 \pm 0$ & $1 \pm 1^{\mathrm{a}}$ & $0 \pm 0$ & $0 \pm 0$ & $0 \pm 0$ & $0.3 \pm 0.4^{\mathrm{a}}$ \\
\hline & $\mathrm{F}$ & $0 \pm 0$ & $0 \pm 0$ & $0 \pm 0$ & $0 \pm 0$ & $0 \pm 0$ & $0 \pm 0$ & $0 \pm 0$ & $0 \pm 0$ \\
\hline \multirow[t]{2}{*}{ BGLD } & $\mathrm{D}$ & $14 \pm 4^{\mathrm{a}}$ & $21 \pm 6^{\mathrm{a}}$ & $17 \pm 4^{\mathrm{a}, \mathrm{b}}$ & $43 \pm 12^{\mathrm{a}}$ & $39.0 \pm 12.2^{\mathrm{a}}$ & $33.8 \pm 19.1^{\mathrm{a}}$ & $49.1 \pm 18.1^{\mathrm{a}, \mathrm{b}}$ & $122.0 \pm 43.5^{\mathrm{a}}$ \\
\hline & $\mathrm{F}$ & $4 \pm 1$ & $3 \pm 1$ & $6 \pm 3 b$ & $13 \pm 4$ & $5.5 \pm 3.0$ & $3.9 \pm 3.3$ & $8.7 \pm 5.3$ & $18.1 \pm 8.4$ \\
\hline \multirow[t]{2}{*}{ BMOD } & $\mathrm{D}$ & $1 \pm 1^{\mathrm{a}}$ & $0 \pm 0$ & $2 \pm 4 \mathrm{a}$ & $3 \pm 4 a$ & $0.6 \pm 0.5^{\mathrm{a}}$ & $0 \pm 0$ & $0.4 \pm 0.6^{\mathrm{a}}$ & $1.8 \pm 0.8^{\mathrm{a}}$ \\
\hline & $\mathrm{F}$ & $0 \pm 0$ & $0 \pm 0$ & $0 \pm 0$ & $0 \pm 0$ & $0.6 \pm 0.3$ & $0 \pm 0$ & $0.1 \pm 0.4$ & $0.5 \pm 0.8$ \\
\hline \multirow[t]{2}{*}{ BMAX } & $\mathrm{D}$ & $0 \pm 0$ & $0 \pm 0$ & $0 \pm 0$ & $0 \pm 0$ & $0 \pm 0$ & $0 \pm 0$ & $0 \pm 0$ & $0 \pm 0$ \\
\hline & $\mathrm{F}$ & $0 \pm 0$ & $0 \pm 0$ & $0 \pm 0$ & $0 \pm 0$ & $0 \pm 0$ & $0 \pm 0$ & $0 \pm 0$ & $0 \pm 0$ \\
\hline \multirow[t]{2}{*}{ STRG } & $\mathrm{D}$ & $3 \pm 1$ & $2 \pm 1$ & $8 \pm 3^{\mathrm{a}, \mathrm{b}}$ & $12 \pm 4$ & $1.8 \pm 0.8$ & $1.1 \pm 1.1$ & $13.7 \pm 8.7^{\mathrm{a}, \mathrm{b}}$ & $16.6 \pm 8.9$ \\
\hline & $\mathrm{F}$ & $3 \pm 1$ & $2 \pm 1$ & $5 \pm 3^{\mathrm{b}}$ & $10 \pm 3$ & $2.9 \pm 1.9$ & $2.4 \pm 2.1$ & $8.2 \pm 5.7^{\mathrm{b}}$ & $13.6 \pm 6.6$ \\
\hline
\end{tabular}

$\mathrm{MC}=$ Movement category; $\mathrm{D}=$ Defense; $\mathrm{F}=$ Forwards; $\mathrm{AP}=$ All players. $\mathrm{P}=$ Period; $\mathrm{STND}=$ Standing; $\mathrm{FSTA}=$ Forward start; $\mathrm{FGLD}=$ Gliding/cruising forward; FMOD=Moderate intensity forward skating; FMAX=High/maximal intensity forward skating; $\mathrm{BGLD}=\mathrm{Gliding}$ /cruising backward; $\mathrm{BMOD}=$ Moderate intensity backward skating; $\mathrm{STRG}=$ Struggling. Game Total=sum of movements for all three periods; Values given are the Mean \pm SD. $a=$ significantly different from forwards. $b=$ significantly different from Period 1 and 2

Table 3. Mean $( \pm \mathrm{SD})$ heart rate measurements for forwards and defense during each period and complete ice hockey games

\begin{tabular}{|c|c|c|c|c|c|c|c|c|}
\hline \multirow[t]{2}{*}{ Variables } & \multicolumn{2}{|c|}{ Period 1} & \multicolumn{2}{|c|}{ Period 2} & \multicolumn{2}{|c|}{ Period 3} & \multicolumn{2}{|c|}{ Game } \\
\hline & $\mathbf{F}$ & D & $\mathbf{F}$ & D & $\mathbf{F}$ & D & $\mathbf{F}$ & D \\
\hline Mean shift HR $\left(b \times \mathrm{min}^{-1}\right)$ & $172 \pm 6$ & $170 \pm 1$ & $175 \pm 6$ & $169 \pm 4$ & $175 \pm 7$ & $168 \pm 3$ & $174 \pm 6$ & $168 \pm 3$ \\
\hline Peak shift HR $\left(b \times \min ^{-1}\right)$ & $180 \pm 7^{\mathrm{a}}$ & $177 \pm 3^{\mathrm{a}}$ & $183 \pm 6^{\mathrm{a}}$ & $177 \pm 8^{\mathrm{a}}$ & $183 \pm 7^{\mathrm{a}}$ & $179 \pm 3^{\mathrm{a}}$ & $182 \pm 6^{\mathrm{a}}$ & $178 \pm 5^{\mathrm{a}}$ \\
\hline $\begin{array}{l}\text { Mean recovery HR between } \\
\text { shifts }\left(b \times \min ^{-1}\right)\end{array}$ & $139 \pm 9^{\mathrm{b}}$ & $132 \pm 4^{b}$ & $138 \pm 10^{\mathrm{b}}$ & $136 \pm 6^{\mathrm{b}}$ & $136 \pm 8^{b}$ & $132 \pm 7^{\mathrm{b}}$ & $137 \pm 8^{\mathrm{b}}$ & $135 \pm 4^{\mathrm{b}}$ \\
\hline Lowest HR between shifts $\left(b \times \min ^{-1}\right)$ & $119 \pm 9^{b, c}$ & $112 \pm 4^{\mathrm{b}, \mathrm{c}}$ & $118 \pm 10^{\mathrm{b}, \mathrm{c}}$ & $117 \pm 6^{\mathrm{b}, \mathrm{c}}$ & $116 \pm 9^{\mathrm{b}, \mathrm{c}}$ & $114 \pm 6^{\mathrm{b}, \mathrm{c}}$ & $118 \pm 9^{\mathrm{b}, \mathrm{c}}$ & $117 \pm 5^{\mathrm{b}, \mathrm{c}}$ \\
\hline
\end{tabular}

$\mathrm{HR}=$ heart rate; $\mathrm{F}=$ forward; $\mathrm{D}=$ defense; $\mathrm{b}=$ =beats. $\mathrm{a}=$ significantly different from mean shift $\mathrm{HR}$ within period. $\mathrm{b}=$ significantly different from mean and peak shift HR within period. $\mathrm{c}=$ significantly different from mean and peak shift HR and mean recovery HR between shifts within period

it decreased significantly below the HR's recorded during game (Table 4).

\section{DISCUSSION}

The evaluation of the physical demands of sport are multifaceted involving physiological assessments, an analysis of the different movement patterns, the time spent performing these activities during competition, including certain physiological measurements during competition to assess the in- tensity requirements of the game. Some early research investigating time motion, HR and fitness of university level ice hockey players was over 30 years ago (Green et al., 1976). Since that research, there has been an increase in both the physical and fitness attributes of players, as well as changes in the demand of the game, which is presently thought to be played at a higher intensity. In addition, different strategies have also emerged. Despite recent research in women's hockey (Jackson et al., 2016), no research has quantified the types and duration of movements performed in men's uni- 
Table 4. Mean $( \pm \mathrm{SD})$ heart rate measurements for forwards and defense during the intermissions between periods of men's ice hockey games

\begin{tabular}{|c|c|c|c|c|}
\hline \multirow[t]{2}{*}{ Variables } & \multicolumn{2}{|c|}{$1^{\text {st }}$ Intermission } & \multicolumn{2}{|c|}{$2^{\text {nd }}$ Intermission } \\
\hline & $\mathbf{F}$ & D & $\mathbf{F}$ & D \\
\hline Intermission mean HR $\left(\mathrm{b} \times \min ^{-1}\right)$ & $109 \pm 7^{\mathrm{a}}$ & $105 \pm 6^{\mathrm{a}}$ & $110 \pm 7^{\mathrm{a}}$ & $104 \pm 4^{\mathrm{a}}$ \\
\hline Intermission low $\mathrm{HR}\left(\mathrm{b} \times \mathrm{min}^{-1}\right)$ & $97 \pm 7^{\mathrm{b}}$ & $94 \pm 5^{b}$ & $96 \pm 6^{b}$ & $93 \pm 3^{b}$ \\
\hline
\end{tabular}

$\mathrm{HR}=$ heart rate; $\mathrm{F}=$ forward; $\mathrm{D}=$ defense; $\mathrm{b}=$ beats. $\mathrm{a}=$ significantly different from mean and peak shift $\mathrm{HR}$ and mean and low recovery HR from Table 3 during the game. $b=$ significantly different from all other game HR's from Table 3 .

versity ice hockey. However, various studies have investigated fitness and skating characteristics of players (Geithner et al., 2006; Lafontaine, Lamontagne \& Lockwood, 2008; Bracko et al., 1998; Falinger, Kruisselbrink \& Fowles, 2007; Gilenstam, Thorsen \& Henriksson-Larsen, 2011), performed longitudinal comparisons of fitness (Montgomery, 2006; Quinney et al., 2008), examined position differences (Vescovi et al., 2006) and have investigated different physiological measurements during games (Spiering, Wilson, Judelson, \& Rundell, 2003; Jackson et al., 2016) in players of different levels and sex. Our findings indicate that male university ice hockey players present with a high level of fitness in a variety of categories with only a few differences noted between players in the forward and defense positions. Players in both positions spend more than half of the game gliding forward, with positional requirements of playing, either defense or forward, eliciting some differences in movement patterns. The present results indicate that HR rapidly increases to near maximum levels in all players during each shift within competition regardless of position, with this increase in HR response being observed as well during short duration, on-ice sprint testing.

Assessment of hockey player fitness has become a cornerstone of both male and female player evaluation, athlete health and return to play after injury at all levels of hockey (amateur, university, national hockey league (NHL) draftees and professional players) (Montgomery, 1988; Cox et al., 1995; Game, Voaklander, Syrotuik \& Bell, 2003; Montgomery 2006; Burr et al., 2008; Quinney et al., 2008; Jackson et al., 2016). Despite the suggestion that ice hockey is an "anaerobic" sport, the physical and fitness demands of the game and the repetition of certain activities, physical contact involved, as well as required positional differences (forwards vs. defense) during the three 20 minute periods suggest this would be an oversimplification (Vescovi et al., 2006; Jackson et al., 2016). The current study completed an extensive evaluation of fitness parameters observing that university hockey players present with high levels of fitness in several different categories (body composition, anaerobic, musculo-skeletal, agility and aerobic) supported by other research in men's (Green et al., 1976; Vescovi et al., 2006; Burr et al., 2008) and women's ice hockey (Bracko, 2001; Geithner et al., 2006; Ransdell \& Murray, 2011; Jackson et al., 2016). Our findings revealed more similarities than differences between player positions. For instance, although defense had significantly higher fatigue index on the anaerobic cycle test (RACT) and a lower peak HR during on ice sprinting (ROIST) compared to forwards, no other fitness differences were noted. In comparison to the research conducted over 30 years ago (Green et al., 1976), the present study observed players to be $2 \%$ taller, $11 \%$ heavier and achieved $5 \%$ higher on relative aerobic fitness. This trend in the differences in height, body mass and anaerobic power was also observed in NHL players over a 26 year period (Quinney et al., 2008). Other research has shown a greater relative aerobic fitness in collegiate forwards compared to defense (Peyer, Pivamik, Eisenmann \& Vorkapich, 2001), with defense players being heavier than forwards in NHL draft aged players (Vescovi et al., 2006). As well, defense players in the NHL were taller, heavier and have lower relative aerobic fitness compared to forwards (Quinney et al., 2008) and this is likely somewhat due to NHL teams intentionally drafting larger players into the defense position to accommodate the increased physicality of ice hockey at this level (Montgomery, 2006). Conversely, in an analysis of a similar sample of NHL drafted players reported by Vescovi et al. (2006), and Burr et al (2008) they found eight fitness variables (excluding body composition) that were higher in defense than forwards and one variable (relative aerobic fitness VO2max) that was higher in forwards. Thus, it appears that any differences in the various indices of fitness between player positions may be somewhat dependent on level of play (i.e. University vs. entry draft aged vs. NHL) or related to differences in player selection practices of the type of player recruited to play University hockey versus NHL (Montgomery, 2006; Burr et al., 2008). Regardless, these findings underlie the importance of fitness testing in evaluating players, as well as for player positions in order to best design an athlete preparation training program. Future research should select, design and incorporate fitness testing specific to the goaltender position in ice hockey (Bell et al., 2008).

Research has used video analysis, global position systems, HR, thermoregulatory and various blood parameters to assess the physical demands experienced by athletes during actual sport competition with the validity, reliability and limitations of the various methods being reviewed (Dobson \& Keogh, 2007; Barris \& Button; 2008). Despite these methods, the ability to accurately quantify all the movement components of athletes during competitive games can be challenging. The combination of videotaping actual competitions and later coding the frequency of movements carried out and the time spent performing them using custom designed or commercially available software applications has been termed TMA of sport (Dobson \& Keogh, 2007; Barris \& Button, 2008; Forbes et al. 2013; Jackson et al., 2016). Despite recent TMA research of university ice 
hockey in women (Jackson et al., 2016), there seems to be no research that quantifies the types and duration of movement patterns in men's hockey despite some earlier studies that included some descriptive aspects of the game but did not provide an analysis of movements (Selinger et al., 1972; Thoden \& Jette, 1975; Green et al., 1976). Knowing the types of movements, the frequency they are performed, and the time spent performing them is valuable information to the athlete and coach for training preparation, designing sport specific assessments, and the development of game strategies.

The present study revealed that the majority of time spent in the various activities during a University ice hockey game for all players was forward gliding $(60 \%)$ followed by skating forward at a moderate intensity $(17 \%)$, standing (9\%), gliding backward (8\%), struggling (2\%), forward sprint starts $(2 \%)$ and forward maximal sprinting (1\%). Backward sprinting or backward skating at a moderate intensity were not frequently observed by any player (all $<1 \%$ ) during competition. Unfortunately, there is a lack of published data to compare these findings. However, the hierarchy of observed movement patterns aligns closely with women university ice hockey with a minor exception (Jackson et al., 2016). Men glided almost twice as long as women (60 vs. $36 \%$, respectively) whereas women skated forward at a moderate intensity for long times than men (31 vs. 17\%, respectively) and struggled longer (6 vs. $2 \%$, respectively) during university ice hockey. Despite a similar order of game activities performed, these findings outline some differences in the amount of time spent performing certain activities between male and female university players.

Some expected differences in movement patterns between the two primary positions in ice hockey were observed. Defense stood, glided backwards and skated backwards at a moderate intensity as well as performed backwards sprint starts more frequently and for longer times compared to forwards during games. Forwards skated forward at a moderate intensity more frequently and for a greater duration while gliding and performing forward sprint starts for longer times compared to defense. We hypothesized that there may be differences in movement patterns between the three periods of play due to changes in game strategies which may depend on the score of the game or the possibility of an accumulation of fatigue. Both forwards and defense performed more sprint starts and moderate skating movements in the forward direction and for longer periods of time in the third period compared to first two periods. As well, all players glided backward and struggled for position or for the puck for greater periods of time in the third period. However, no other differences in movement patterns were observed between periods suggesting that the physical and mental fatigue aspects of the game may not have adversely influenced player movement as the game progressed.

In comparison to data reported by Green et al. in 1976, the mean game playing time of University hockey players was 9\% shorter (20:08 vs. 22:05, min: s) while mean shift time was $30 \%$ shorter ( 65 vs. $88 \mathrm{~s}$ ) and the mean number of shifts per game were $18 \%$ fewer (15 vs. 18) than observed in the present study. As well, the mean number of play stoppages by referees was $129 \%$ fewer ( 0.5 vs. 2.3$)$ and the mean time of play stoppages was $18 \%$ shorter (11 vs. $26 \mathrm{~s}$ ) with a similar recovery time between shifts $(2 \%, 4: 38$ vs. 4.30 , min: s), respectively. These data suggest that there have been changes in the characteristics of the game supporting the contention that player's shifts are shorter and more intense based on fewer and shorter play stoppages in a shift. Interestingly, Green et al (1976) also measured skating velocities during competition and found that forwards (center + wingers) achieved a mean of $270 \mathrm{~m} \times \mathrm{s}^{-1}$ while defense averaged 159 $\mathrm{m} \times \mathrm{s}^{-1}$ during ice hockey games. While the present study did not measure skating velocity during actual games, maximal skating velocities were measured during the ROIST test and

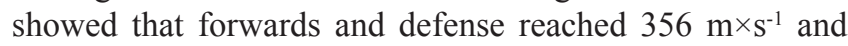
$348 \mathrm{~m} \times \mathrm{s}^{-1}$ over $15 \mathrm{~m}$, respectively. These observations may suggest that current players and the game of University ice hockey is "faster" compared to over 30 years ago (Green et al., 1976).

Cardiovascular fitness is often overlooked in athletes and sports that are thought to be more anaerobic (sprint) in nature such as ice hockey. However, various research has shown a high HR response to repeated sprinting in different exercise modes (Buchheit, Laursen \& Ahmaidi, 2007; Little \& Williams, 2007; Meckel, Casorla \& Eliakim, 2009; Lee, Lin \& Cheng, 2011) as well as during men's and women's ice hockey (Green et al., 1976; Spiering et al., 2003; Jackson et al., 2016). Despite the majority of time spent gliding and skating at a moderate intensity during a game, HR continued to increase throughout a player's shift that lasted less than $65 \mathrm{~s}$ and reached an average of 96 and $90 \%$ and a peak of 100 and $96 \%$ of HRmax for forwards and defense, respectively. Furthermore, our ROIST which included seven repeated skating sprints lasting less than three seconds also resulted in a continual increase in HR throughout the test eliciting HR's that averaged 87 and 93\% of HRmax. Given that an ice hockey shift is often less than one minute during which players glide $60 \%$ of the time and perform low to moderate intensity activities $36 \%$ of the time, it is paradoxical that HR continues to increase to near maximum during a shift. As well, there were consistent increases in HR responses in some players during shifts that did not include sprints at a high intensity. It is possible, that the combination of physiological and psychological (emotional) stress experienced during competition likely contributes to the high heart rate response (Fernandez, et al., 2014). Other possibilities include increased sympathetic neural activity, elevated catecholamines, increased chemoreceptor stimulation (e.g. hydrogen ion), greater afferent neural activity from upper and lower body limb movement, thermoregulatory demands and increased aerobic metabolic demand are other possible factors (Jackson et al., 2016). Heart rates decreased to an average of 73 and $80 \%$ of HRmax between shifts for defense and forwards reaching a mean low between 63 and $65 \%$ of HRmax. As well, HR decreased to similar low levels during the intermission between periods (51-59\% of HRmax). These findings are similar to Green et al., (1976) and other research in female ice hockey players (Spiering et al., 2003; Jackson et al., 2016). These findings also underscore that ice hockey player's reach near maxi- 
mum HR levels during most shifts, and although these HR's recover, they remain somewhat elevated in between shifts while sitting on the bench throughout a game. Thus, the role that cardiovascular fitness plays in the performance and health of the players should not be underestimated (Atwal, Porter \& MacDonald, 2002) and further research is suggested to investigate the underlying stimuli to this rapid HR response in ice hockey players.

\section{Limitations}

The present study used a convenient sample of players from the same team and caution is advised if generalizations are to be made to other CIS teams and comparison should not be made to other levels of ice hockey (e.g., professional or international hockey). The games chosen for observation were in-season (CIS league games) and may not reflect the demands associated with playoff or championship games. As well, the sample sizes were small within each of the player position groups increasing the likelihood of a type II error in the statistical analyses. Visual observation of video-taped sport performance relies on the skill of the observer to accurately judge the different types of movements and the length of time they were performed. Despite our high inter and intra tester reliability, some movements, especially those that occur rapidly, may have been underestimated. Maximal backward skating and backward sprint starts were two categories that were absent or very infrequently observed but this finding was similar to our study in female ice hockey (Jackson et al., 2016). Furthermore, we did not separate movement activities when a player was in possession of the puck or not and that may have influenced the type of activity performed. Finally, there are differences in coach strategy that can influence game play that were beyond the control of the investigators.

\section{Practical Applications}

As previously mentioned, physiological assessment of athletes in a sport such as ice hockey consisting of a high level of fitness can be used to assist with player evaluation, selection, training programming, athlete health and player help with decisions for return to play after an injury. The knowledge of the types of movement patterns and the duration that these activities are performed during games can be used to support the selection of appropriate fitness assessments and the design and periodization of sport specific training programs. This would also aid the development of game simulated workouts for team members with limited ice time or are not playing in a particular game based on coaching decisions and would benefit from specific game simulation exercise (Jackson et al., 2016). The lack of difference in the fitness profiles of forwards and defense in the present study would suggest that similar supplementary training prescriptions would be feasible and practical for players in both positions. As well, there was some evidence in the present study that University level players and the game have changed and that players are taller, heavier and faster and the overall intensity of the game has increased over the past few decades.

\section{CONCLUSIONS}

Male university ice hockey players present with a high level of fitness in a variety of categories of fitness emphasizing the need for a well-rounded conditioning program. During ice hockey games, players spend the most time gliding forward and performing moderate intensity activity interspersed with shorter and less frequent high intensity movements. There were some differences in movement patterns between forwards and defense since players in the defense position are required to skate backwards and have some different responsibilities than forwards. Finally, despite the majority of the game time spent in low to moderate intensity activities, the intermittent nature of activities in a hockey shift coupled with the psychological stress of competition contributed to near maximal HR responses in all players.

\section{ACKNOWLEDGEMENTS}

The authors thank Jessie Gill, Ben Davis, Ciaran O'Flynn, the involved players, coaches and training staff.

\section{REFERENCES}

Atwal, S., Porter, J., \& MacDonald, P. (2002). Cardiovascular effects of strenuous exercise in adult recreational hockey: the hockey heart study. Canadian Medical Association Journal, 166(3), 303-307.

Barris, S.\&Button, C.(2008).Areview of vision-based motion analysis in sport. Sports Medicine, 38(12), 1025-1043. http://dx.doi:10.2165/00007256-200838120-00006.

Beaver, W. L., Wasserman, K., \& Whipp, B. J. (1986). A new method for detecting anaerobic threshold by gas exchange. Journal of Applied Physiology, 60, 2020-2027.

Bell, G., Snydmiller, G., \& Game, A. (2008). An investigation of the type and frequency of movement patterns of national hockey league goaltenders. International Journal of Sports and Performance, 3, 80-87. http://dx. doi: org/10.1123/ijspp.3.1.80.

Bracko, M.R. (2001). On-ice performance characteristics of elite and non-elite woman's ice hockey players. Journal of Strength and Conditioning Research, 15(1), 42-47.

Bracko, M. R., Fellingham, G. W., Hall, L. T., Fisher, A. G., \& Cryer, W. (1998). Performance skating characteristics of professional ice hockey forwards. Sports Medicine, Training and Rehabilitation, 8(3), 251-263. http://dx. doi.org/10.1080/15438629809512531.

Buchheit, M., Laursen, P. B., \& Ahmaidi, S. (2007). Parasympathetic reactivation after repeated sprint exercise. American Journal of Physiology - Heart and Circulatory Physiology, 293, H133-H141. http://dx. doi:10.1152ajpheart.00062.2007.

Burr, J., Jamnik, V., Baker, J., MacPherson, A., Gledhill, N., \& McGuire, E. (2008). Relationship of physical fitness test results and hockey playing potential in elite-level ice hockey players. Journal of Strength and Conditioning Research, 22(5), 1535-1543. http://dx.doi:10.1519/ jsc.0b013e318181ac20.

Canadian Society for Exercise Physiology (2013). CSEP- 
PATH Physical Activity Training for Health. Ottawa: Canadian Society for Exercise Physiology.

Cox, M. H., Miles, D. S., Verde, T. J., \& Rhodes, E. C. (1995). Applied physiology of ice hockey. Sports Medicine, 19(3), 184-201. http://dx.doi: 10.2165/00007256199519030-00004.

Dobson, B. P. \& Keogh, J. W. L. (2007). Methodological issues for the application of time-motion analysis research. Strength and Conditioning Journal, 29(2), 48-55.

Falinger, C. M., Kruisselbrink, L.D., \& Fowles, J. R. (2007). Relationships to skating performance in competitive hockey players. Strength and Conditioning Journal, 21(3), 915-922.

Fernandez-Fernandez, J., Boullosa, D.A., Sanz-Rivas, D., Abreu, L., Filaire, E., \& Mendez-Villanueva, A. (2014). Psychophysiological stress response during training and competition young female competitive tennis players. International Journal of Sports Medicine, 36(1), 22-28. http://dx.doi: 10.1055/s0034-1384544.

Forbes, S. C., Kennedy, M. D., \& Bell, G. J. (2013). Time-motion analysis, heart rate, and physiological characteristics of international canoe polo athletes. Journal of Strength and Conditioning Research, 27(10), 2816-2822.

Game, A., Voaklander, D., Syrotuik, D., \& Bell, G. (2003). Incidence of exercise-induced bronchospasm and exercise induced hypoxaemia in female varsity hockey players. Research in Sports Medicine, 11: 11-21. http:// dx.doi: 10.1080/15438620390192971.

Geithner, C. A., Lee, A. M., \& Bracko, M. R. (2006). Physical and performance differences among forwards, defensemen, and goalies in elite women's ice hockey. Journal of Strength and Conditioning Research, 20(3), 500-505.

Gilenstam, K. M., Thorsen, K., \& Henriksson-Larsen. (2011). Physiological correlates of skating performance in women's and men's ice hockey. Journal of Strength and Conditioning Research, 25(8), 2133-2142.

Gledhill, N. \& Jamnik, V. (2007). Detailed assessment protocols for NHL entry draft players. Toronto: York University.

Green, H., Bishop, P., Houston, M., McKillop, R., Norman, R., \& Stothart, P. (1976). Time-motion and physiological assessments of ice hockey performance. Journal of Applied Physiology, 40(2), 159-163.

Jackson, J., Snydmiller, G., Game, A., Gervais, P., \& Bell, G. (2016). Movement characteristics and heart rate profiles displayed bzy female university ice hockey players. International Journal of Kinesiology \& Sport Science, 4(1), 43-54. http://dx.doi:10.7575/aiac.ijkss.v.4n.1p.43.

Lafontaine, D., Lamontagne, M., \& Lockwood, K. (1998). Time-motion analysis of ice-hockey skills during games. International Symposium on Biomechanics in Sport, 16, 481-484.

Lee, C. L., Lin, J. C., \& Cheng, C. F. (2011). Effect of caffeine ingestion after creatine supplementation on intermittent high-intensity sprint performance. European Journal of Applied Physiology, 111, 1669-1677. http:// dx.doi: 10.1070/s00421-010-1792-0.
Little, T., \& Williams, A. (2007). Effects of sprint duration and exercise: rest ratio on repeated sprint performance and physiological responses in professional soccer players. Journal of Strength and Conditioning Research, 21(2), 646-648.

Meckel, Y., Casorla, T. \& Eliakim, A. (2009). The influence of basketball dribbling on repeated sprints. International Journal of Coaching Science, 3(2), 43-56.

Montgomery, D. L. (1988). Physiology of ice hockey. Sports Medicine, 5, 99-126. http://dx.doi: 10.2165/00007256198805020-00003.

Montgomery, D. L. (2006). Physiological profile of professional hockey players - a longitudinal comparison. Applied Physiology, Nutrition and Metabolism, 31(3), 181-185. http://dx.doi:10.1139/H06-012.

Peterson, B. J., Fitzgerald, J. S. Dietz, C. C., Ziegler, K. S., Ingraham, S. J., Baker, S. E., \& Snyder, E. M. (2015). Aerobic capacity is associated with improved repeated shift performance in hockey. Journal of Strength and Conditioning Research, 29(6), 1465-1472.

Peyer, K. L., Pivarnik, J. M., Eisenmann, J. C., \& Vorkapich, M. (2011). Journal of Strength and Conditioning Research, 25(5), 1183-1192.

Quinney, H. A., Smith, D., \& Wenger, H. A. (1984). A field test for the assessment of abdominal muscular endurance in professional ice hockey players. Journal of Orthopeadic and Sports Physical Therapy, 6, 30-33. http:// dx.doi: 10.2519/jospt.1984.6.1.30.

Quinney, H. A., Dewart, R., Game, A., Snydmiller, G., Warburton, D., \& Bell, G. (2008). A 26 year physiological description of a National Hockey League team. Applied Physiology, Nutrition and Metabolism, 33(4), 753-760. http://dx.doi:10.1139/H08-051.

Ransdell, L. B. \& Murray, T. (2011). A physical profile of elite female ice hockey players from the USA. Journal of Strength and Conditioning Research, 25(9), 2358-2363.

Sayers, S. P, Harackiewicz, D. V, Harman, E. A., Frykman, P. N, \& Rosenstein, M. T. (1999). Cross-validation of three jump power equations. Medicine and Science in Sport and Exercise, 31(4): 572-577. http:// dx.doi: 10.1097/00005768-199904000-00013.

Seliger, V., Kostka, V., Grusova, D., Kovac, J., Machovcova, J., Pauer, M., \& Urbankova, R. (1972). Energy expenditure and physical fitness of ice-hockey players. European Journal of Applied Physiology, 30(4), 283-291. http://dx.doi: 10.1007/BF00696119.

Spiering, B. A., Wilson, M. H., Judelson, D. A., \& Rundell, K. W. (2003). Evaluation of cardiovascular demands of game play and practice in Women's Ice Hockey. Journal of Strength and Conditioning Research, 17(2), 329-333.

Stanula, A. \& Roczniok, R. (2014). Game intensity analysis of elite adolescent ice hockey players. Journal of Human Kinetics, 44, 211-221. http://dx.doi: 10.2478/ hukin-2014-0126.

Taylor, J. Basketball: Applying time motion data to conditioning. (2003). Strength and Conditioning Journal, 25(2), 57-64.

Thoden, J. S. \& Jette, M. (1975). Aerobic and anaerobic ac- 
tivity patterns in junior and professional hockey. Movement (Special Hockey), 2, 145-153.

Vescovi, J. D., Murray, T. M., Fiala, K.A., \& Vanheest, J. L. (2006). Off-ice performance and draft status of elite ice hockey players. International Journal of Sports, Physiology and Performance, 1, 207-221. http://dx.doi: org/10.1123/ijspp.1.3.207.
Wilson, K., Snydmiller, G., Game, A., Quinney, H. A., \& Bell, G. (2010). The development and reliability of a repeated anaerobic cycling test in female ice hockey players. Journal of Strength and Conditioning Research, 24(2), 580-584.

Yuhasz, M. (1996). Physical fitness and sports appraisal laboratory manual. London: The University of Western Ontario. 